\title{
Study on Response Characteristics of Wind Vibration of United Framework of Transformer Substations Considering the Influence of Busbars and Insulators
}

\author{
Dong Xie ${ }^{1}$, Yi Xiong ${ }^{1}$, Xuejun Tang ${ }^{1}$, Luping $\mathrm{Li}^{2}$, Fenghua Jin², Xiangmin Chen ${ }^{2}$, Zhaoyang Zhang ${ }^{1}$, \\ Hongchuan Dong ${ }^{1}$, Heng Ding ${ }^{1}$, Jiang Feng ${ }^{2}$, Hao Zhang ${ }^{2}$ and Miao Gong ${ }^{2}$ \\ ${ }^{1}$ State Grid Hubei Economic Technology Research Institute, Wuhan, 430077; \\ ${ }^{2}$ Changsha University of Science and Technology, Changsha, 410114
}

\begin{abstract}
The full united frameworks (FUF) of transformer substations belong to wind-sensitive towering structures, and wind load is a decisive control load. Wires, lower leads, and busbars hang on united frameworks. Such suspension component will inevitably affect the wind-induced response characteristics of united frameworks, which must be considered in design. In this study, a $500 \mathrm{kV}$ full united substation framework was used as the study object. Six busbars was installed in longitudinal direction on the framework. With the help of finite element analysis software ANSYS, based on random vibration theory, the wind-induced vibration response of the united framework was calculated and analyzed in frequency domain. The wind induced vibration displacement response and the spatial distribution rule of the wind vibration coefficient under the wind load in different wind directions were obtained. The calculation results show that, with the existence of longitudinal busbars, the fluctuation displacement response and the wind vibration coefficient of the transformer framework decreased, which reduced the alternating load of the transformer framework, with the location of the maximum displacement of the fluctuating displacement response transferred to the busbars. The existence of the busbars has little effect on the mean displacement response of the transformer framework, which can be ignored in the design phase of the transformer framework.
\end{abstract}

Keywords - transformer substation; full united framework (FUF); busbar; wind vibration response; wind vibration coefficient; dynamic characteristics; finite element analysis (FEA)

\section{INTRODUCTION}

With the increasing height of substation frame, the collapse of substation frameworks caused by strong wind happens frequently ${ }^{[1]}$, causing tremendous economic losses and serious social impacts. Therefore, in recent years, the research on the wind vibration response and the wind vibration coefficient of the full united transformer frameworks has become a hot topic for the majority of scholars and engineers.

Compared with a low voltage power framework, the load and the self height and span of $500 \mathrm{kV}$ and $1000 \mathrm{kV}$ full united frameworks (FUF) largely increase, so that this type of combined substation have the characteristics of high height, heavy load and low natural frequency. According to the need of structural layout, the frame and crossbeams and waybeams are set at different elevations of this type of FUF. This makes the windward side of the structure larger than that of the single portal type structure, and the whole structure tends to be flexible, making the wind load effect significant. Therefore, the structure is wind sensitive, and wind load is often the main or even decisive control load of design.

Currently, the influence of the busbars and insulators has been seldom considered in domestic and overseas studies on the wind vibration response characteristics of FUF. For this reason, in this study, the united $500 \mathrm{kV}$-transformer framework was used as the study object, and 6 pipe busbars were installed in the longitudinal direction of the united framework (i.e. 0 degree wind direction). Through three-dimensional solid modeling and the finite element analysis (FEA) software ANSYS, based on the random vibration theory, the wind induced vibration response of the united framework was calculated and analyzed in frequency domain. We obtained the wind induced vibration displacement response and the spatial distribution rule of the wind vibration coefficient under the wind load in different wind directions and different average velocities under the effect of busbars and insulators, providing a reference for the optimization design of wind resistant structure and defect diagnosis.

\section{Calculation Model of Wind Vibration Response} OF UNITED FRAMEWORK

\section{A. Motion Equation of Substation Frame}

The equation of structural vibration induced by fluctuating wind loads $F_{w}(t)$ on a substation frame can be expressed as [1]:

$$
M \ddot{x}(t)+C \dot{x}(t)+K x(t)=F_{w}(t)
$$

where

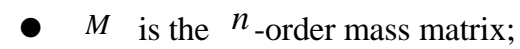

- $C$ is the $n_{\text {-order damping matrix; }}$

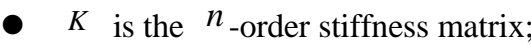

- $x(t), \dot{x}(t)$, and $\ddot{x}(t)$ are the displacement, velocity and acceleration vectors, respectively;

- $F_{w}(t)$ is node pulsating wind load vector. 
Use modal method to decouple (1), and let:

$$
x(t)=[\phi] y(t)
$$

where $[\phi]=\left[\phi_{1}, \phi_{2}, \phi_{3} \ldots . . \phi_{n}\right]$ and is a vibration mode vector.

According to the orthogonality of the main vibration mode, the structural damping is assumed to be proportional damping, and the Vibration equation of the $j$-th modality is expressed as ${ }^{[3]}$ :

$$
\begin{aligned}
& \ddot{q}_{j}+2 \varsigma_{j}\left(2 \pi n_{j}\right) \dot{q}_{j}+\left(2 \pi n_{j}\right)^{2} q_{j} \\
& =\frac{\phi_{j}^{T} F_{w}(t)}{M_{j}}=F_{j}(t)
\end{aligned}
$$

where

- $n_{j}$ is the self vibration frequency of the $j$-th modality;

- $\varsigma_{j}$ is the damping ratio of the ${ }^{j}$-th modality;

- $M_{j}$ is the generalized mass of the ${ }^{j}$-th modality;

- $F_{j}(t)$ is the generalized modal force of the ${ }^{j}$-th modality.

\section{B. Simulation Model of Wind Load}

1) Average wind speed model

The variation law of the average wind speed along the height can be approximately described by exponential function [1]:

$$
\frac{\bar{V}(z)}{\bar{V}\left(z_{s}\right)}=\left(\frac{z}{z_{s}}\right)^{\alpha}
$$

where

- $\bar{V}(z)$ is the average wind speed at height $z \mathrm{~m}$, $\mathrm{m} / \mathrm{s}$.

- $\bar{V}\left(z_{s}\right)$ is the average wind speed at reference height, $\mathrm{m} / \mathrm{s}$;

- generally, the reference height was set to $Z_{s}=10 \mathrm{~m}$ and $\bar{V}\left(z_{s}\right)$ was set to $30 \mathrm{~m} / \mathrm{s}$ for calculation;

- $\alpha$ is surface roughness index;

- the studied object located in B class region, and we set $\alpha=0.16$ [4][5].

\section{2) Wind load calculation model}

The wind speed is composed of the steady part and the pulsating part, and the former is larger than the latter. Generally, wind load can be expressed as ${ }^{[4][5]}$

$$
\begin{aligned}
& F_{w}=w(z, t) A \\
& =\frac{\gamma \mu_{s}}{2 g} A[\bar{V}(z)+V(z, t)]^{2}
\end{aligned}
$$

where

- $A$ is the structural area under wind pressure, $m^{2}$;

- $\bar{V}(z), V(z, t)$ represent 1 hour average velocity and the pulsating velocity part at height $\mathrm{z}, \mathrm{m} / \mathrm{s}$;

- $\mu_{s}$ is the shape coefficient of the structure.

Since

$$
\begin{aligned}
& {[\bar{V}(z)+V(z, t)]^{2}} \\
& =\bar{V}^{2}(z)\left[1+2 \frac{V(z, t)}{\bar{V}(z)}+\frac{V^{2}(z, t)}{\bar{V}^{2}(z)}\right]
\end{aligned}
$$

Therefore, the wind load can be expressed as ${ }^{[5]}$ :

$$
F_{w}=F_{w}^{(1)}+F_{v}+F_{v^{2}}
$$

It is clear in (7) that the wind load on the framework consists of three parts. Because the fluctuating wind speed is much smaller than the average wind speed, the square of fluctuating wind speed can be neglected when calculating wind load. Then, we have ${ }^{[6]}$ :

$$
F_{w} \approx F_{w}^{(1)}+F_{v}
$$

The pulsating wind load of the node is ${ }^{[1]}$ :

$$
F_{j}(t)=\rho C_{L i} V v(t) A_{i}
$$

where

- $\rho$ is air density, $\mathrm{kg} / \mathrm{m}^{3}$;

- $A_{i}$ is the sum of all the projection areas of the steel pipe on the windward face at framework node $i, m^{2}$;

- $C_{L i}$ is the average wind pressure coefficient at node $i$.

C. Solution to Framework Motion Equation

For a small damping system of substation framework, the 
spectral density function of the displacement vector $x(t)$ under the action of wind load is ${ }^{[1]}$

$$
S_{x}(2 n \pi)=\sum_{j=1}^{n} \phi_{j}^{2}\left|H_{j}(2 \pi i n)\right|^{2} S_{F_{j}}(2 \pi n)
$$

where

- $\phi_{j}$ is the vibration vector of type $j$;

- $S_{F_{j}}(2 \pi n)$ is the self spectral density function of generalized force $S_{F_{j}}(t)$;

- $\left|H_{j}(2 \pi i n)\right|$ is the module of the frequency response function of generalized force $S_{F_{j}}(t)$;

- The autocorrelation function of generalized force $S_{F_{j}}(t)$ is [1]:

$$
S_{F_{j}}(\tau)=\sum_{r=1}^{n} \sum_{s=1}^{n} \phi_{r j} \phi_{s k} R_{F}(r, s, \tau)
$$

Conduct Fourier transform for the above equation to obtain the self spectral density of generalized force ${ }^{[1]}$ :

$$
S_{F_{j}}(2 n \pi)=\sum_{r=1}^{n} \sum_{s=1}^{n} \phi_{r j} \phi_{s k} S_{F}(r, s, n)
$$

The expression of its cross spectral density is ${ }^{[1]}$ :

$$
\begin{aligned}
& S_{F_{r} F_{s}}(2 \pi n)=\frac{1}{2 \pi} \int_{0}^{\infty} R_{F_{r} F_{s}}(\tau) e^{-2 \pi i n \tau} d \tau \\
& =\rho^{2} C_{L r} C_{L s} A_{r} A_{s} V_{r} V_{s} S_{v r v s}(2 n \pi)
\end{aligned}
$$

where

- $C_{L r}, C_{L s}$ are the average wind pressure coefficients of nodes $r, s$, respectively, without dimension;

- $V_{r}, V_{s}$ are the average wind speed of nodes $r, s$, $m / s$;

- $S_{v r v s}(2 n \pi)$ is the cross spectral density of pulse wind speed between nodes $r, s$.

In this study, the fluctuating wind speed power spectrum was firstly converted to the fluctuating wind pressure power spectrum ${ }^{[7]}$. Then it was converted to the pulsating wind force power spectrum, so that the power spectrum density of fluctuating wind with respect to frequency can be obtained ${ }^{[8]}$.

$$
S_{F_{i}}(n)=16 \alpha u_{z} \bar{w}_{10} \frac{x^{2}}{n\left(1+x^{2}\right)^{4 / 3}} A_{i}^{2}
$$

where

- $S_{F_{i}}(n)$ is the pulsating wind force spectrum of the $i$ -th node;

- $\bar{w}_{10}$ is the average wind pressure, $\mathrm{kN} / \mathrm{m}^{2}$;

- $A_{i}$ is the net projection area of the related cross sections of the ${ }^{i}$-th node, $m^{2}$.

\section{FINITE ELEMENT CALCULATION OF WIND VIBRATION} RESPONSE OF UNITED FRAMEWORKS

\section{A. 3D Entity Model of Computed Object}

\section{1) Body model of FUF}

The 3D solid model of the computed FUF is shown in Figure I. Cross braces of the FUF were set up at the height of $12 \mathrm{~m}$ and $23.5 \mathrm{~m}$, with chord member being a steel tube, and web member being a corner steel member. Unstiffened flange connection was adopted for beam pipe joint, while stiffened flange connection was adopted for steel pipe chord. Steel tubular chord, angle steel web and bolt connection formed the lattice steel beam. The joint frame was equipped with a frame beam at the height of $28 \mathrm{~m}$. The beams of the joint frame shown in Figure I are numbered 1 to 7 from left to right.

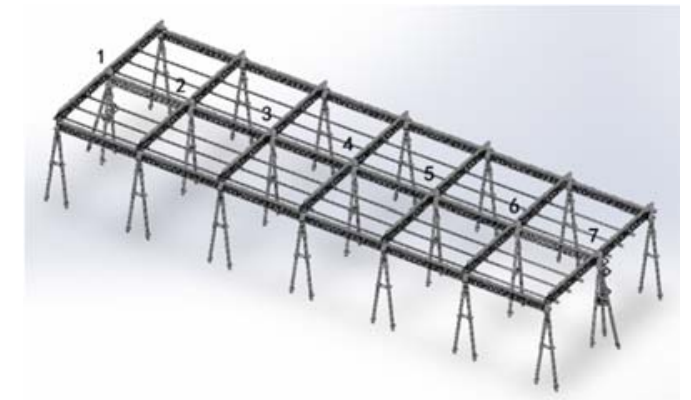

FIGURE I. THE 3D SOLID MODAL OF THE COMPUTED FUF

\section{2) Simplified model of busbar}

The busbars were arranged along the longitudinal direction (i.e., the direction of the coordinate axis, or the direction of 0 degree wind direction). A soft connection between the busbar and the frame beam was adopted, and the insulator was installed on the lower lead wire. The angle between the lower lead wire and the vertical direction was 15 degree, and the mass of insulator, $m_{j y}$, was set to $57 \mathrm{~kg}$. The pipe busbar was set as hollow tube and the density was evenly distributed, with outer diameter $150 \mathrm{~mm}$, inner diameter $136 \mathrm{~mm}$, and mass per unit length $2.7 \mathrm{~kg} / \mathrm{m}$.

The connection between the substation frame and the busbars, the definition of the direction of the incoming line of the substation framework, the direction angle of the wind and coordinate system are shown in Figure II. 


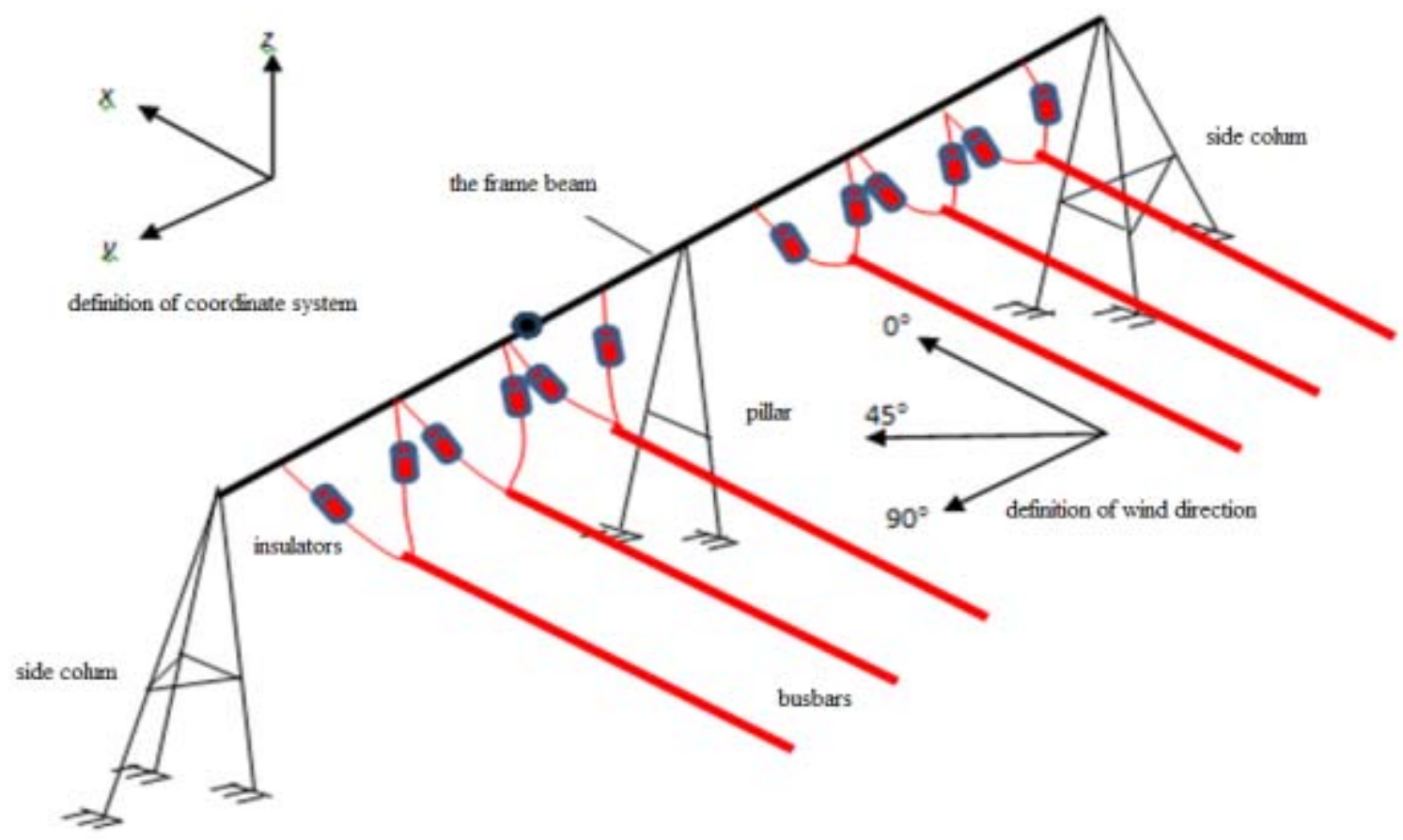

FIGURE II. THE CONNECTION BETWEEN THE SUBSTATION FRAME AND THE BUSBARS THE DEFINITION OF THE WIND DIRECTION AND COORDINATE SYSTEM

\section{B. Boundary Condition Setting}

\section{1) Connection of column and foundation}

At the connection of the column and the foundation of a united framework, the constraint is zero according to the displacement of three coordinates. For any calculation node at the connection between the column and the foundation, $x=0, y=0, z=0$.

2) Connection between the frame and the wires

There is a complex connection between the united $500 \mathrm{kV}$ substation framework and the conductor and ground wire. In order to simplify the calculation, the boundary conditions formed by the conductor / ground wire (called wire hereafter for simplicity) is processed as follows (the definition of wind direction is shown in Figure II).

(1) In calculating the wind load response of $0^{\circ}$ wind direction angle, only $F_{x}, F_{z}$ load was considered while ignoring $F_{y}$ load; the values of $F_{y}$ and $F_{z}$ were in accordance with related design specification;

(2) In calculating the wind load response of $90^{\circ}$ wind direction angle, $F_{x}, F_{y}$ and $F_{z}$ load was considered; the values of $F_{x}$ and $F_{z}$ were in accordance with related design specification. $F_{y}$ is the half of the horizontal load on a wire exerted by wind, i.e., ${ }^{[5]}$ :

$$
F_{y}=\frac{1}{2} F_{d}
$$

where $F_{d}$ is the horizontal loads produced by wind speed across a transmission line, $k N$.

I.

The equivalent load of $500 \mathrm{kV}$ FUF wire is shown in Table

TABLE I. EQUIVALENT LOAD OF 500KV FUF WIRE

\begin{tabular}{cccc}
\hline & & & \\
Wind direction $\backslash$ Component force(kN) & $F_{x}$ & $F_{y}$ & $F_{z}$ \\
\hline $0^{\circ}$ wind direction & 30.0 & - & 23.9 \\
$45^{\circ}$ wind direction & 20.3 & 17.7 & 23.9 \\
$90^{\circ}$ wind direction & 65.0 & 35.4 & 23.9 \\
\hline
\end{tabular}

C. Calculation of Wind Load Displacement Response of Different Wind Direction Angles

The 3D solid model of the substation framework shown in Figure I was divided into grids and wind load in different directions was added respectively. Using finite element software ANSYS, the wind-induced response of the transformer framework was calculated and the following results were obtained.

1) Displacement response calculation under $0^{\circ}$ wind direction load effect

(1) At average wind speed $15 \mathrm{~m} / \mathrm{s}$

Figure III and IV show the mean response and pulsating 
response cloud charts of the transformer framework with busbars at average wind speed of $15 \mathrm{~m} / \mathrm{s}$.

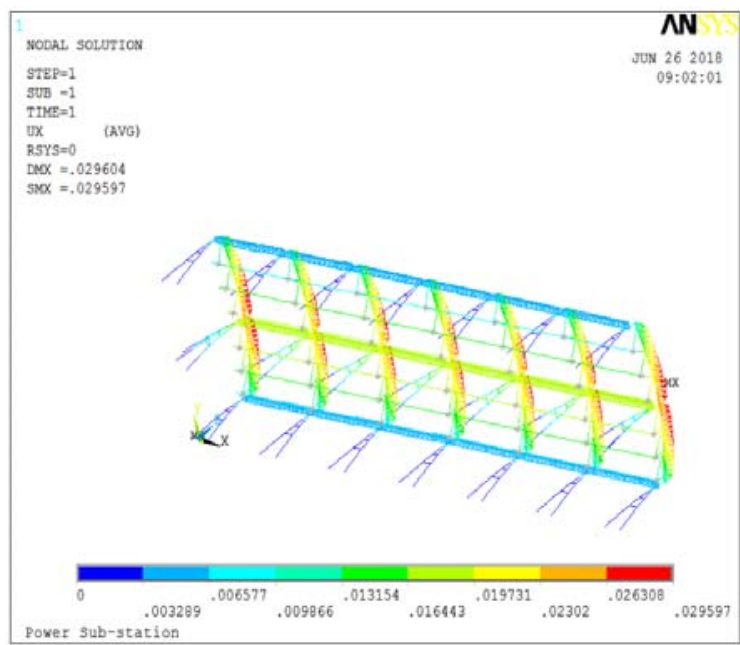

FIGURE III. MEAN RESPONSE DISTRIBUTION OF SUBSTATION FRAME $\left(0^{\circ}\right.$ WIND DIRECTION, $\left.15 \mathrm{M} / \mathrm{S}\right)$

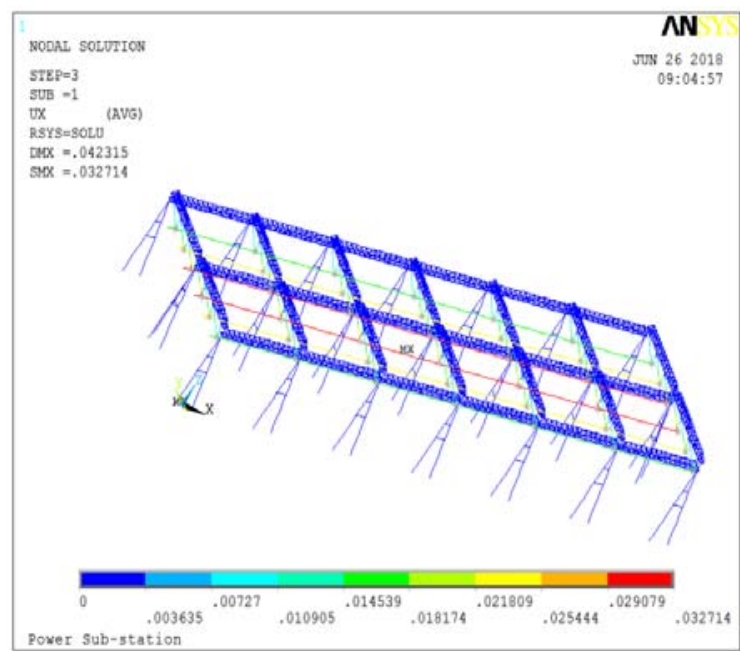

FIGURE IV. PULSATING WIND VELOCITY RESPONSE DISTRIBUTION OF SUBSTATION FRAME $\left(0^{\circ}\right.$ WIND DIRECTION, $\left.15 \mathrm{M} / \mathrm{S}\right)$

It is clear in Figure III and IV that the areas with larger average response of framework occur in the middle position of each crossbeam (near the middle column). The displacement response of the first frames and seventh frames is the most prominent. Among them, the maximum mean response displacement appears in the middle column of the seventh structures, with the maximum displacement value of $0.030 \mathrm{~m}$; the areas with the largest pulsation response appear in the 2 middle busbars, with the maximum pulsating response displacement value of $0.033 \mathrm{~m}$.

(2) At average wind speed $20 \mathrm{~m} / \mathrm{s}, 25 \mathrm{~m} / \mathrm{s}$ and $30 \mathrm{~m} / \mathrm{s}$

According to the results of finite element calculation, at average wind speed of $20 \mathrm{~m} / \mathrm{s}, 25 \mathrm{~m} / \mathrm{s}$ and $30 \mathrm{~m} / \mathrm{s}$, although the mean response amplitude of the united framework varies, the spatial distribution of the wind-induced vibration response of the frame is similar to average wind speed $15 \mathrm{~m} / \mathrm{s}$. When the average wind speed is $30 \mathrm{~m} / \mathrm{s}$, the maximum mean response displacement value is $0.118 \mathrm{~m}$, and the maximum fluctuation response displacement is $0.160 \mathrm{~m}$.

Both the mean response amplitude and the pulsation response amplitude increase with the increase of average wind speed.

2) Displacement response calculation under $90^{\circ}$ wind direction load effect

(1) At average wind speed $15 \mathrm{~m} / \mathrm{s}$

Figure V and VI show the mean response and pulsating response cloud charts of the transformer framework with busbars at this average wind speed.

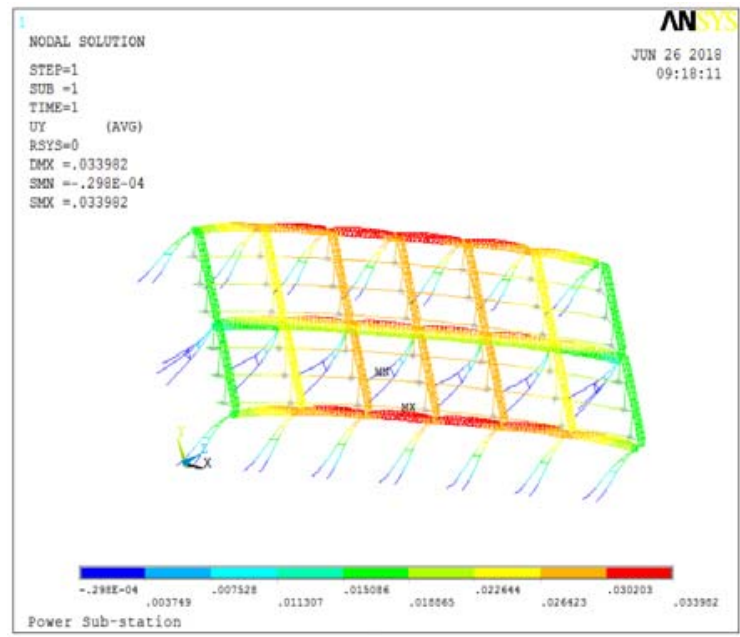

FIGURE V MEAN RESPONSE DISTRIBUTION OF SUBSTATION FRAME ( $90^{\circ}$ WIND DIRECTION, $\left.15 \mathrm{M} / \mathrm{S}\right)$

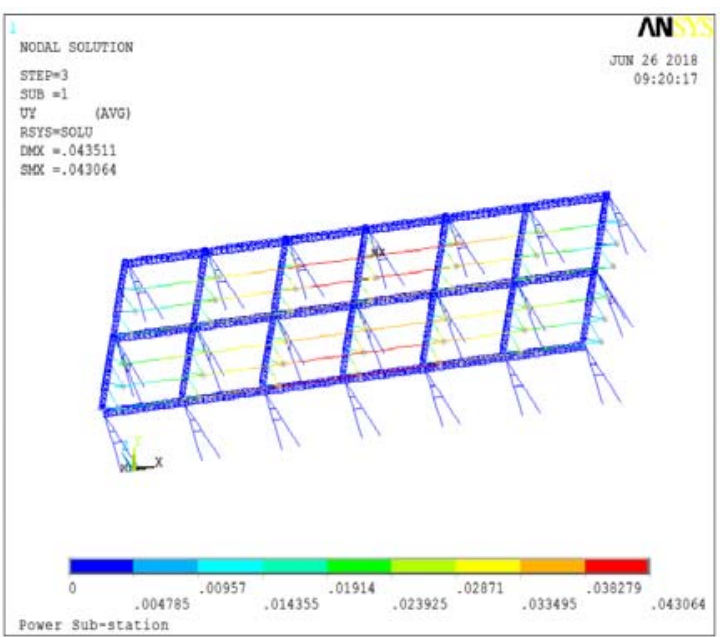

FIGURE VI. PULSATING WIND VELOCITY RESPONSE DISTRIBUTION OF SUBSTATION FRAME ( $90^{\circ}$ WIND DIRECTION, 15M/S)

It is clear in Figure $\mathrm{V}$ and VI that the areas with larger average response of framework occur in the middle position of each waybeam (near the both sides of the 4-th framework). The maximum mean response displacement is $0.034 \mathrm{~m}$; the areas with the largest pulsation response appear in the middle position of the $1^{\text {st }}, 2^{\text {nd }}, 5^{\text {th }}$ and $6^{\text {th }}$ busbars (near the 4-th 
framework), with the maximum pulsating response displacement value of $0.043 \mathrm{~m}$.

(2) At average wind speed $20 \mathrm{~m} / \mathrm{s}, 25 \mathrm{~m} / \mathrm{s}$ and $30 \mathrm{~m} / \mathrm{s}$

According to the results of finite element calculation, at average wind speed of $20 \mathrm{~m} / \mathrm{s}, 25 \mathrm{~m} / \mathrm{s}$ and $30 \mathrm{~m} / \mathrm{s}$, although the mean response amplitude of the united framework varies, the spatial distribution of the wind-induced vibration response of the framework is similar to average wind speed $15 \mathrm{~m} / \mathrm{s}$. When the average wind speed is $30 \mathrm{~m} / \mathrm{s}$, the maximum mean response displacement value is $0.136 \mathrm{~m}$, and the maximum fluctuation response displacement is $0.206 \mathrm{~m}$.

Both the mean response amplitude and the pulsation response amplitude increase with the increase of average wind speed.

3) Displacement response calculation under $45^{\circ}$ wind direction load effect

(1) At average wind speed $15 \mathrm{~m} / \mathrm{s}$

Figure VII and VIII show the mean response and pulsating response cloud charts of the transformer framework with busbars at this average wind speed.

(1) In Figure VI(a), the peak area of the average displacement response of each crossbeam is located near the middle column. The first beam and the seventh beam are the most prominent, the maximum response being the seventh crossbeam, i.e., $0.0093 \mathrm{~m}$.

(2) In Figure VI(b), The average displacement response of both waybeams of the framework is larger than that of the middle column. The maximum mean displacement response is the first column of waybeam, and the maximum value distribution area is near the both sides of the fourth frame, with maximum value $0.0106 \mathrm{~m}$.

(3) In Figure VIII(a), the response displacement of the crossbeam and waybeam with busbars is small. The peak area of the maximum pulsation response displacement locates on the $3^{\text {rd }}$ busbar, with pulsation response displacement of $0.0248 \mathrm{~m}$

(4) In Figure VIII(b), the response displacement of the crossbeam and waybeam with busbars is small. The peak area of the maximum pulsation response displacement locates on the $4^{\text {th }}, 5^{\text {th }}$, and $6^{\text {th }}$ busbars, with pulsation response displacement of $0.040 \mathrm{~m}$.

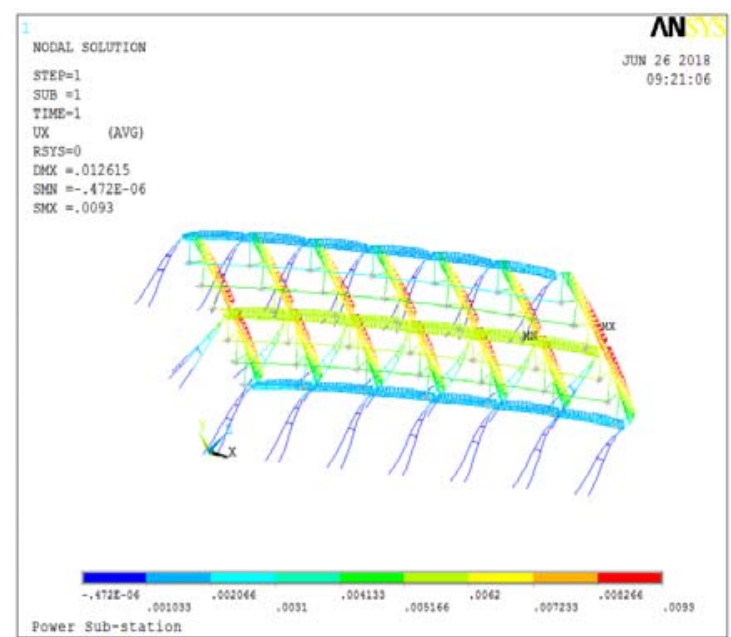

(a) Mean response distribution of frame transverse beam

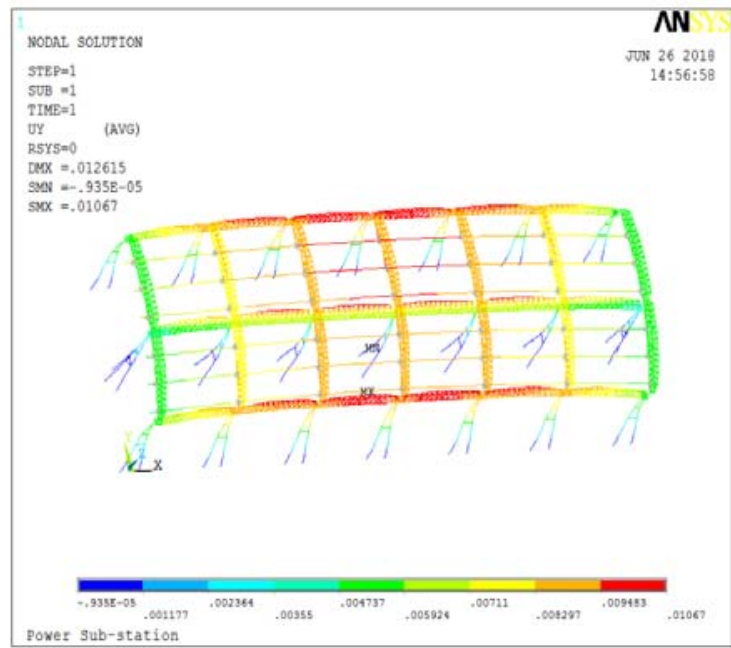

(b)Mean response distribution of frame longitudinal beam

FIGURE VII. MEAN RESPONSE DISTRIBUTION OF SUBSTATION FRAME ( $45^{\circ}$ WIND DIRECTION, 15M/S)

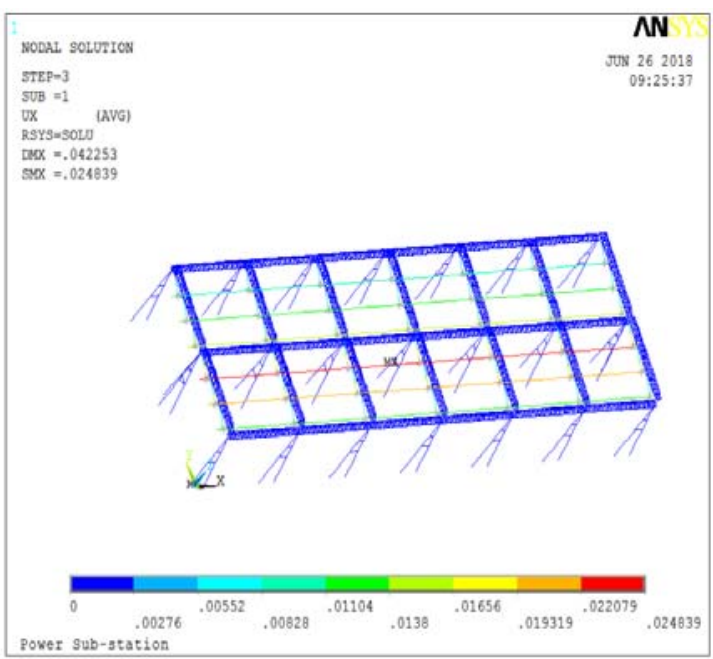

(a) Fluctuating response distribution of frame transverse beam 


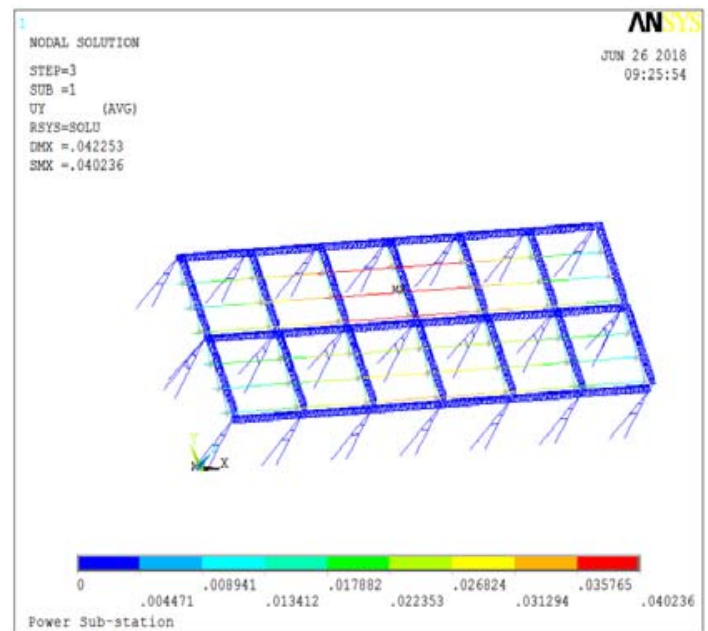

(b) Fluctuating response distribution of frame longitudinal beam FIGURE VIII. PULSATING RESPONSE DISTRIBUTION OF SUBSTATION FRAME ( $45^{\circ}$ WIND DIRECTION, $15 \mathrm{M} / \mathrm{S}$ )

(2) At average wind speed $20 \mathrm{~m} / \mathrm{s}, 25 \mathrm{~m} / \mathrm{s}$ and $30 \mathrm{~m} / \mathrm{s}$

According to the results of finite element calculation, at average wind speed of $20 \mathrm{~m} / \mathrm{s}, 25 \mathrm{~m} / \mathrm{s}$ and $30 \mathrm{~m} / \mathrm{s}$, although the mean response amplitude of the united framework varies, the spatial distribution of the wind vibration response of the framework is similar to average wind speed $15 \mathrm{~m} / \mathrm{s}$. When the average wind speed is $30 \mathrm{~m} / \mathrm{s}$, the maximum mean response displacement value of crossbeam is $0.0372 \mathrm{~m}$, the maximum mean response displacement value of busbar is $0.0427 \mathrm{~m}$, and the maximum fluctuation response displacement is $0.1209 \mathrm{~m}$.

Both the mean response amplitude and the pulsation response amplitude increase with the increase of average wind speed.

\section{WIND VIBRATION COEFFICIENT CALCULATION FOR UNITED FRAMEWORK}

\section{A. Calculation Model of Wind Vibration Coefficient}

Displacement wind vibration coefficient is one of the most commonly used wind vibration coefficients. According to the regulation of building structure load, the formula of wind vibration coefficient is calculated as ${ }^{[9]}$ :

$$
\beta=\frac{\mu_{u}+g \sigma_{u}}{\mu_{u}}
$$

where

- $\beta$ is the wind vibration coefficient without dimension;

- $\mu_{u}$ is the displacement of average wind load, $m$;

- $\sigma_{u}$ is the displacement with variance under fluctuating wind load, $m$;

- $g$ is the Davenport peak factor without dimension. where

$$
\sigma_{u}=\sqrt{\int_{0}^{+\infty} G_{u}(n) \mathrm{d} n}
$$

where $G_{u}(n)$ the power spectral density of displacement:

$$
g=\sqrt{2 \ln \left(v_{0} T\right)}+\frac{0.5772}{\sqrt{2 \ln \left(v_{0} T\right)}}
$$

where

- $T$ is the observation time of one hour, $h$;

- $v_{0}$ is the zero crossing rate in unit time, $\frac{1}{h}$;

$$
\begin{aligned}
v_{0} & =\frac{1}{2 \pi} \sqrt{\frac{\lambda_{2}}{\lambda_{0}}}, \text { spectral moment; } \\
\lambda_{i} & =2 \int_{0}^{+\infty} n^{i} G(n) \mathrm{d} n
\end{aligned}
$$

B. Calculation and Analysis of the Wind Vibration Coefficient under Different Wind Direction Angles

The following points were selected as the calculated points of wind vibration coefficients: points of the $4^{\text {th }}$ framework's middle column, and points of the column intersecting the $1^{\text {st }}$ waybeam and the $4^{\text {th }}$ framework, as well as the surrounding waybeam, as shown by the areas designated by red lines in Figure IX.

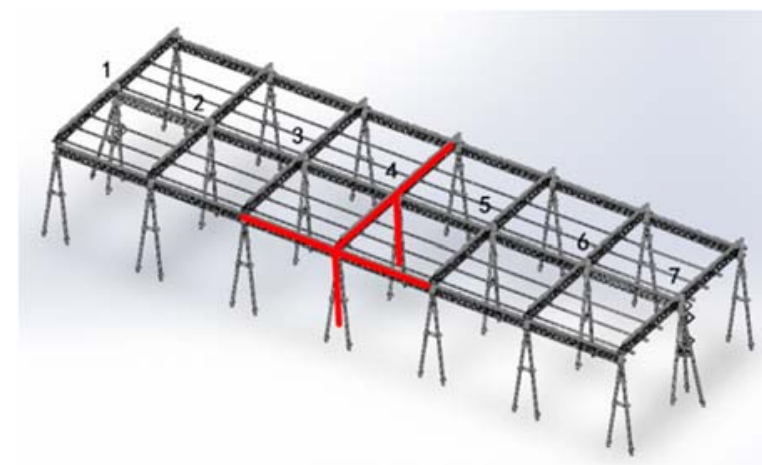

FIGURE IX. CALCULATED POINT LOCATION OF THE WIND-INDUCED DYNAMIC COEFFICIENT OF THE FUF

1) Wind vibration coefficient in $0^{\circ}$ wind angle

When the wind angle is $0^{\circ}$, the relationship between the wind vibration coefficient of the observed node of the $4^{\text {th }}$ crossbeam and the average wind speed at reference height is shown in Table II. 
TABLE II. RELATIONSHIP BETWEEN WIND VIBRATION COEFFICIENT OF $4^{\mathrm{TH}}$ CROSSBEAM AND AVERAGE WIND SPEED AT REFERENCE HEIGHT IN $0^{\circ}$ WIND ANGLE DIRECTION

\begin{tabular}{ccccc}
\hline Node average wind speed(m/s) & 15 & 20 & 25 & 30 \\
& & & & \\
\hline 1358 & 1.35 & 1.41 & 1.46 & 1.50 \\
351 & 1.30 & 1.34 & 1.39 & 1.48 \\
363 & 1.03 & 1.05 & 1.06 & 1.12 \\
\hline
\end{tabular}

The maximum wind vibration coefficient appears at the 1358 node when the average wind speed is $30 \mathrm{~m} / \mathrm{s}$. Therefore, taking this point as a representative, the relationship between the wind vibration coefficient of the point and the average wind speed at reference height is plotted, as shown in Figure $\mathrm{X}$.

The curve in Figure $\mathrm{X}$ is fitted, resulting in fitting formula:

$$
\beta_{i}(\bar{v})=-2 \times 10^{-4} \bar{v}^{2}+0.019 \bar{v}+1.11
$$

It is clear in Figure $\mathrm{X}$ and (19), the wind vibration coefficient and average wind speed show linear relationship. For node numbers 1358, 351, and 363, when the average wind speed increases from $15 \mathrm{~m} / \mathrm{s}$ to $30 \mathrm{~m} / \mathrm{s}$, the wind vibration coefficient increases $11.1 \%, 13.8 \%$ and $8.7 \%$, respectively.

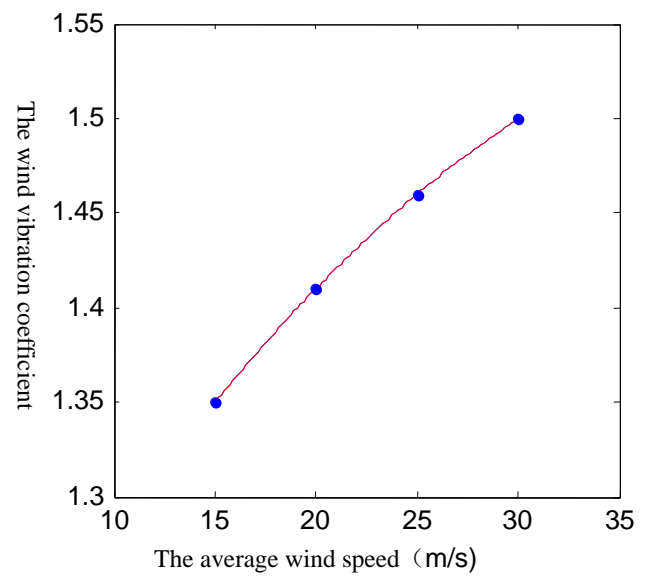

FIGURE X. RELATIONSHIP BETWEEN WIND VIBRATION COEFFICIENT OF $1358^{\mathrm{TH}}$ NODES AND AVERAGE WIND SPEED OF REFERENCE HEIGHT

2) Wind vibration coefficient in $90^{\circ}$ wind angle

When the wind angle is $90^{\circ}$, the relationship between the wind vibration coefficient of the observed node of the $1^{\text {st }}$ waybeam and the average wind speed at reference height is shown in Table III.

TABLE III. RELATIONSHIP BETWEEN WIND VIBRATION COEFFICIENT OF $1^{\text {ST }}$ WAYBEAM AND AVERAGE WIND SPEED AT REFERENCE HEIGHT IN 90 WIND ANGLE

\begin{tabular}{ccccc}
\hline Node average wind speed(m/s) & 15 & 20 & 25 & 30 \\
& & & & \\
\hline 607 & 1.43 & 1.53 & 1.72 & 1.92 \\
1882 & 1.33 & 1.47 & 1.68 & 1.85 \\
888 & 1.14 & 1.19 & 1.34 & 1.49 \\
\hline
\end{tabular}

When the wind angle is $90^{\circ}$, the maximum wind vibration coefficient appears at the 607 node when the wind speed is $30 \mathrm{~m} / \mathrm{s}$. Therefore, taking this point as a representative, the relationship between the wind vibration coefficient of the point and the average wind speed at reference height is plotted, as shown in Figure XI.

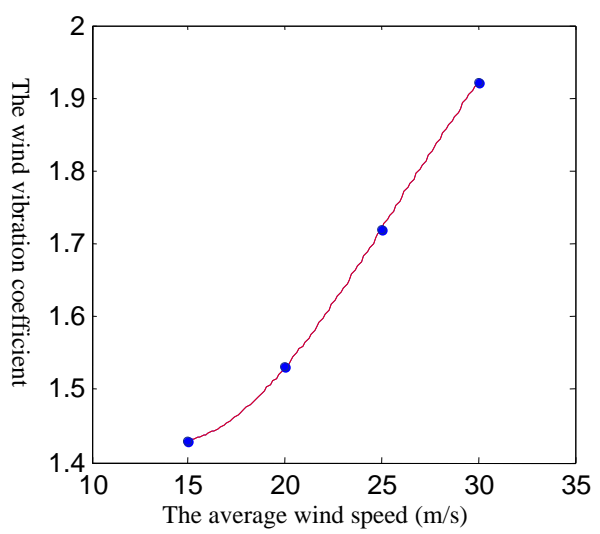

FIGURE XI. RELATIONSHIP BETWEEN WIND VIBRATION COEFFICIENT OF $607^{\mathrm{TH}}$ NODES AND AVERAGE WIND SPEED OF REFERENCE HEIGHT

The curve in Figure XI is fitted, resulting in fitting formula:

$$
\beta_{i}(\bar{v})=-1.067 \bar{v}^{3}+0.0082 \bar{v}^{2}-0.168 \bar{v}+2.47
$$

For node numbers 607, when the average wind speed increases from $15 \mathrm{~m} / \mathrm{s}$ to $30 \mathrm{~m} / \mathrm{s}$, the wind vibration coefficient increases $34.3 \%$.Under the wind load of $90^{\circ}$ wind, the increase rate of the wind vibration coefficient caused by average wind speed increase is greater than that under the wind load of $0^{\circ}$ wind direction.

3) Wind vibration coefficient in $45^{\circ}$ wind angle

When the wind angle is $45^{\circ}$, the relationship between the wind vibration coefficient of the observed node of the $4^{\text {th }}$ crossbeam and the $1^{\text {st }}$ waybeam and the average wind speed at reference height is shown in Tables IV and V.

TABLE VI. X COMPONENT

\begin{tabular}{ccccc}
\hline $\begin{array}{c}\text { Node average wind } \\
\text { speed(m/s) }\end{array}$ & 15 & 20 & 25 & 30 \\
\hline 607 & 1.15 & 1.22 & 1.34 & 1.43 \\
1882 & 1.08 & 1.16 & 1.28 & 1.34 \\
888 & 1.01 & 1.04 & 1.09 & 1.24 \\
1358 & 1.30 & 1.41 & 1.50 & 1.56 \\
351 & 1.07 & 1.09 & 1.10 & 1.33 \\
363 & 1.04 & 1.05 & 1.07 & 1.27 \\
\hline
\end{tabular}


TABLE V. Y COMPONENT

\begin{tabular}{ccccc}
\hline $\begin{array}{c}\text { Node average wind } \\
\text { speed(m/s) }\end{array}$ & 15 & 20 & 25 & 30 \\
\hline 607 & 1.14 & 1.22 & 1.31 & 1.49 \\
1882 & 1.09 & 1.11 & 1.13 & 1.16 \\
888 & 1.06 & 1.08 & 1.09 & 1.12 \\
1358 & 1.12 & 1.14 & 1.17 & 1.28 \\
351 & 1.08 & 1.13 & 1.15 & 1.19 \\
363 & 1.03 & 1.05 & 1.08 & 1.16 \\
\hline
\end{tabular}

When the wind angle is $45^{\circ}$, the maximum wind vibration coefficients in $\mathrm{x}$ and $\mathrm{y}$ directions appear at the nodes 607 and 1358 when the wind speed is $30 \mathrm{~m} / \mathrm{s}$. Therefore, taking these two points as representatives, the relationship between the wind vibration coefficient of the points and the average wind speed at reference height is plotted, as shown in Figure XII and XIII.

$$
\begin{gathered}
\beta_{i}(\bar{v})=1.067 \times 10^{-4} \bar{v}^{3}-0.0062 \bar{v}^{2}+0.134 \bar{v}+0.16 \\
\beta_{i}(\bar{v})=2.667 \times 10^{-5} \bar{v}^{3}-0.002 \bar{v}^{2}+0.067 \bar{v}+0.65
\end{gathered}
$$

For node numbers 607, when the average wind speed increases from $15 \mathrm{~m} / \mathrm{s}$ to $30 \mathrm{~m} / \mathrm{s}$, the wind vibration coefficients increases $30.7 \%$ and $24.3 \%$ for $\mathrm{x}$ and $\mathrm{y}$ direction, respectively.

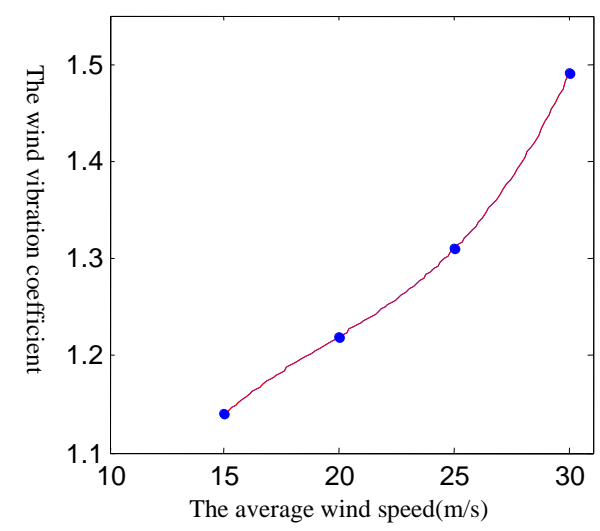

FIGURE XII. RELATIONSHIP BETWEEN WIND VIBRATION COEFFICIENT OF $607^{\mathrm{TH}}$ NODES AND AVERAGE WIND SPEED OF REFERENCE HEIGHT

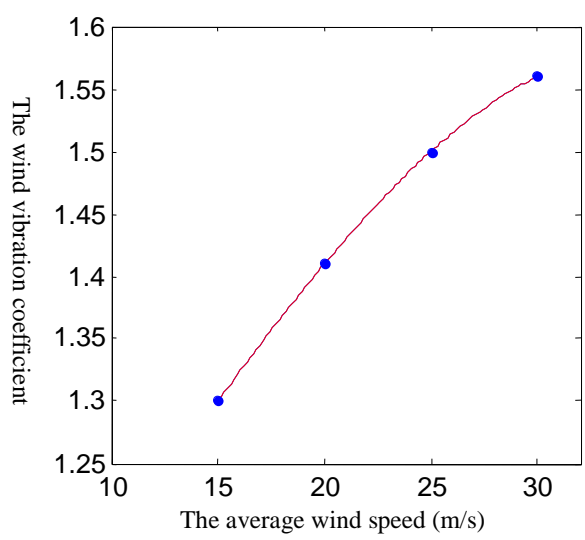
FIGURE XIII. RELATIONSHIP BETWEEN WIND VIBRATION COEFFICIENT OF $1358^{\mathrm{TH}}$ NODES AND AVERAGE WIND SPEED OF REFERENCE HEIGHT

\section{CONCLUSIONS}

(1) Under the load of $0^{\circ}$ wind direction at different average wind speed, areas of larger mean response of the united framework all appear in the middle position of each crossbeam (near the middle column). The displacement of the $1^{\text {st }}$ and $7^{\text {th }}$ frameworks is the most prominent. Among them, the maximum mean response displacement appears in the middle column of the $7^{\text {th }}$ structures. The areas with larger pulsation response appear on the 2 middle busbars. The amplitudes of the mean response and the pulsation response increase with the increase of mean wind speed.

(2) Under the load of $0^{\circ}$ wind direction at different average wind speed, areas of larger mean response of the united framework appear in the middle position of each waybeam (near the two sides of the $4^{\text {th }}$ framework), and the areas with larger pulsation response appear in the middle position of $1^{\text {st }}$, $2^{\text {nd }}, 5^{\text {th }}$ and $6^{\text {th }}$ busbars (near the $4^{\text {th }}$ crossbeam). The amplitude of the mean response and the amplitude of the pulsation response increase with the increase of mean wind speed.

(3) Whether the wind load is in $0^{\circ}, 90^{\circ}$ or $45^{\circ}$, the longitudinally installed busbars have played a role in the actual effect of energy absorber for the wind vibration response of united frameworks. Thus, the fluctuating displacement response and the wind vibration coefficient of the transformer framework are reduced, reducing the alternating load of the transformer framework. The maximum location of the fluctuating displacement response is transferred from the framework itself to the busbar. The existence of the busbar has little effect on the mean displacement response of the substation frame, which can be neglected.

(4) The conclusions of this paper give an inspiration to the designers. In the design of a substation with high frequency of high wind speed, some suspension devices can be designed to absorb the wind vibration response energy of the framework and reduce the amplitude of the wind response of the framework itself, which can improve the safety and reliability of the framework. 


\section{ACKNOWLEDGEMENT}

This research was financially supported by the National Science Foundation. Science and technology project of Hubei electric power company of State Grid (Testing technology and engineering application of damping ratio and wind vibration coefficient of full united substation framework, 52153816001B)

\section{REFERENCES}

[1] Jianzhi Ding. Study on wind vibration response and wind vibration coefficient of $750 \mathrm{kV}$ ultra high voltage substation framework [D]. Xi'an University Of Architecture And Technology, 2012.

[2] Feng Pan, Fang Xie, Yuelong Xing, et al. Wind-induced dynamic response of large steel tube frame for $1000 \mathrm{kV}$ UHV transmission lines to thunderstorm downbursts.

[3] Ding Jianzhi. Wind-induced Vibration Responses and Wind Vibration Factor of $750 \mathrm{kV}$ Overlong Substation Steel Lattice Frame[D].Xi'an University of Architecture and Technology,2012.

[4] Pan Feng, Tong Jianguo. Wind-induced Dynamic Response of Large Thin-walled Steel Tube Frame for $1000 \mathrm{kV}$ Substation[J].Engineering Mechanics2009, 26(10):203-210.

[5] Ministry of Housing and Urban-Rural Development of the People's Republic of China.GB50009-2012 Building structure load specifications[S]. Beijing: China Building Industry Press, 2012.

[6] Zhang Wei. Vibration Analysis of Transmission Line Tower Structure[D]. Harbin Institute of Technology, 2011.

[7] Zhu Dianzhi, Wang Xiuli. Finite Element Analysis and Optimization Design of $750 \mathrm{kV}$ EHV Substation Combined Steel Frame[J].Gansu Science and Technology, 2008, 24(13): 108-110.

[8] Feng Renxiang. Design on the United Frame Structure for the $500 \mathrm{kV}$ Transformer Substation of Wuning in Jinhua[J].Zhejiang Construction, 2014, 31(07): 35-38.

[9] Niu Huawei, Kong Kaige, Chen Yan.500kV Whole Combined Substation Framework Shape Factor of Wind Tunnel Test and Dynamic Response Factor Analysis[J]. Journal of Hunan University (Natural Science), 2015, 42(11): 80-87. 